\title{
MOVING TOWARDS A STATEWIDE APPROACH TO COURT DIVERSION SERVICES IN NSW
}

\section{David Greenberg and Ben Nielsen}

NSW Statewide Community and Court Liaison Service Corrections Health Service

There are significantly higher prevalence rates of severe mental health problems and disorders in correctional centres, compared to the general population. ${ }^{1}$ The Corrections Health Service and the NSW Department of Health undertook a study of the health status of inmates in NSW correctional centres, and reported that approximately one third of males and half of females had a history of mental health assessment and/or treatment by a psychiatrist or a psychologist. ${ }^{2}$ This finding supports the establishment of court-based mental health liaison services for individuals with psychiatric disorders, which divert individuals from court settings to community-based services. One such initiative is the NSW Statewide Community and Court Liaison Service, previously described in the July 2002 issue of the NSW Public Health Bulletin (Volume 13, Number 7). ${ }^{3}$ This article describes the evolution of a statewide approach to court diversion and court liaison in NSW and its context in the overall provision of forensic mental health services.

\section{OVERVIEW OF FORENSIC MENTAL HEALTH POLICY}

A strategic approach to the delivery of forensic mental health services has been addressed in the draft NSW Forensic Mental Health Strategy. ${ }^{4}$ The aim of the strategy is to provide an integrated comprehensive forensic mental health system in NSW and to propose a comprehensive model to support forensic mental health services. The Second National Mental Health Plan identifies the need for improved mental health services for this specific population. ${ }^{5}$ Likewise, the discussion paper Towards a National Approach to Forensic Mental Health is a guide to the development of these improved services. ${ }^{6}$ The discussion paper proposes a comprehensive and integrated statewide approach involving several state government departments providing tertiary specialist forensic mental health services (such as a forensic hospital clinic, a forensic community clinic, a court liaison service, and psychiatric services to prisons). This will work in collaboration with secondary services provided by the local area mental health services (such as general psychiatric hospitals, community mental health services, and private mental health practitioners).

A proposed model for the provision of integrated forensic mental health services in NSW is based on best practice models elsewhere in Australia, New Zealand, and other countries. ${ }^{6}$ Victoria, Queensland, and Western Australia have similar approaches to provision of an integrated statewide model of service delivery. A statewide forensic mental health approach should provide a range of specialist services to the existing local area mental health services across NSW. These specialist services include the following four components: inpatient services provided in secure forensic psychiatric facilities, community forensic mental health services, prison mental health services, and court diversion and court liaison services. These four components must work in unison, and should collaborate closely with existing local area mental health services, to provide effective pathways for comprehensive specialist forensic mental health services.

The United Nations Standard Minimum Rules for the Treatment of Prisoners 1955, Rule 82 (1), states that: '... persons who are found to be insane shall not be detained in prisons and arrangements shall be made to remove them to mental institutions as soon as possible'. ${ }^{7}$ In practice, such people have in the past spent extended periods in prison rather than in hospital. ${ }^{8}$ The development of a new forensic mental health hospital, in an appropriately secure environment outside of prison, is an essential ingredient in the spectrum of services that forensic patients need. An external judiciary process, such as the courts or the NSW Mental Health Review Tribunal, would determine the security locations of mentally ill or mentally disordered defendants and offenders in the forensic system.

The target group for forensic mental health services in NSW includes the formal definition 'forensic patient' as defined in Schedule 1 of the NSW Mental Health Act 1990: that is, people found not guilty by reason of mental illness, people unfit to stand trial, and inmates from the prisons who are usually temporarily transferred under Section 97 and 98 of that Act. ${ }^{9}$ The forensic services may also include offenders or alleged offenders referred directly by the courts, particularly aggressive patients with high treatment needs, sex offenders, stalkers, and arsonists.

\section{COURT DIVERSION AND COURT LIAISON}

Court diversion and court liaison are not synonymous terms but they are closely related.

\section{Court diversion}

Court diversion has been defined as a transfer of mentally ill people from criminal justice system to hospital or community mental health placements. ${ }^{10}$ It involves the access of mentally ill or mentally disordered defendants to mental health services. It does not equate to discontinuation of existing criminal charges, but it does allow the courts to be informed of relevant mental health issues as they relate to the defendant and the community. With this in mind, a formal diversionary measure was included within Sections 32 and 33 of the NSW Mental Health (Criminal Procedures) Act 1990. ${ }^{11}$ These Sections only relate to summary (often minor) offences and not to committal proceedings or indictable offences. 


\section{Court liaison}

Court liaison has a broader meaning, which includes court diversion. It also includes the linking, brokering, and advocating for appropriate care; collaborating with the various agencies and departments in providing continuity of services; and a shared responsibility for the management and care of the forensic client that avoids duplication of tasks and roles by joint stakeholders. ${ }^{12}$ Court liaison sits within a broader framework model for forensic patients and compliments, but does not replicate, the existing local area community mental health services in providing an integrated model of service provision.

\section{NSW STATEWIDE COMMUNITY AND COURT LIAISON SERVICE}

The operational task of the NSW Statewide Community and Court Liaison Service (SCCLS) begins when people with mental health problems or disorders are apprehended by the police. The police, corrective services, legal aid services, and magistrates, bring this specific population to the attention of the court-based SCCLS staff. To improve identification of our target population, we have engaged in educational initiatives and regular consultation with lawyers, custodial staff, and magistrates. Association and collaboration occurs not only in the courthouse but also in other arenas such as police cells, lawyers' offices, and correctional centres. The requirements of confidentiality and informed consent are met at all times.

Psychiatric assessment, and negotiation by our health staff involves liaison with families, mental health services, nongovernment agencies, public prosecutors, lawyers, magistrates, the NSW Department of Corrective Services, general practitioners, and private psychiatrists, among others. The SCCLS also links clients with the existing mental health services provided by Corrections Health within correctional centres. On discharge from prison, the SCCLS staff re-links inmates with mental health problems and mental disorders back to the local area mental health services.

\section{ACCESSTO MENTAL HEALTHTREATMENT}

The SCCLS also assists where appropriate with admissions to psychiatric inpatient facilities, ${ }^{9}$ and advises custodial staff on medications and other health matters. People on orders under Section 32 of the NSW Mental Health (Criminal Procedures) Act 1990, ${ }^{11}$ and people on bail, are linked with the local community mental health centres. ${ }^{3}$ Although the SCCLS provides court liaison services, both in-custody and out-of-custody, it does not provide outpatient psychiatric treatment in the courthouse. Forensic psychiatric treatment is the combined role of an envisaged statewide community forensic service and the existing local area community mental health centres.

\section{COURT REPORTS}

In May 2002, the SCCLS became involved in quality initiatives of the Statewide Court Report Unit of the Clinical Services Directorate, Corrections Health Service. This court reporting program provides comprehensive consultant psychiatric reports for the courts for those individuals in custody housed at the 29 prisons across the state. The reporting service has been highly successful in reducing the report production time from 12 to two weeks. Where a more complex or detailed psychiatric assessment is needed for a person in custody, a forensic psychiatric report can be produced no-matter where the origin of the requesting court.

\section{THE EFFECTIVENESS AND OUTCOMES OF COURT LIAISON SERVICES}

The quality and efficiency of diversion schemes can be measured on a range of health and judiciary performance indicators. These may include quality of life and social wellbeing, rates of re-hospitalisation, rates of incarceration and recidivism, court processing time, and time spent on remand. ${ }^{13}$ A key performance indicator is the ability to successfully negotiate diversion of mentally ill or disordered individuals away from the criminal justice system towards a variety of community and inpatient mental health facilities.

A range of factors may affect the ability of area mental health services to accept the mentally disordered offender. These may include demands on existing services, the perceived dangerousness of the mentally disordered offender, and a myth that prison mental health services are better equipped to manage mentally ill defendants with minor criminal charges. The latter factor is sometimes referred to as 'the criminalisation of the mentally ill', a factor that poses a particular challenge for staff involved with court liaison schemes. ${ }^{14}$ Our court liaison mental health staff play an important role in advocating and facilitating access to community based mental health services as a viable alternative to incarceration for minor offences. ${ }^{4}$ The judiciary, not mental health workers, determine the outcome of judicial proceedings. The longterm benefit from ongoing negotiations with area mental health services is improved access to psychiatric treatment and care for mentally disordered offenders at the interface of the criminal justice system.

\section{CONCLUSION}

The forensic population is a small target group who are relatively under-serviced. This small target group usually requires specific resources and expertise to manage their often complex and serious problems. Court liaison should be seen as part of a spectrum of forensic mental health services that address the needs of this population. 


\section{ACKNOWLEDGEMENTS}

Thank you to Beverley Raphael, Centre for Mental Health, NSW Department of Health, who provided advice on earlier drafts of this article.

\section{REFERENCES}

1. Herman H, Mills J, Doidge G, McGorry P, Singh B. Use of psychiatric services before imprisonment: A survey and case register linkage of sentenced prisoners in Melbourne. Psychological Medicine 1994; 24: 63-68.

2. Butler T and Allnutt S. Mental Health Survey in NSW Correctional Centres. Sydney: Corrections Health Service, 2003.

3. Greenberg DM, Nielsen B. Court diversion in NSW for people with mental health problems and disorders. NSW Public Health Bull 2002; 13: 158-60.

4. NSW Department of Health. Draft NSW Forensic Mental Health Strategy. Sydney: NSW Department of Health, 2002.

5. Australian Health Ministers. Second National Mental Health Plan. Canberra: Commonwealth Department of Health and Family Services, Mental Health Branch, 1998.

6. AHMAC National Mental Health Working Group. Towards a National Approach to Forensic Mental Health. Canberra: Commonwealth Department of Health and Aged Care, Mental Health Branch, 1999.
7. Adopted by the First United Nations Congress on the Prevention of Crime and the Treatment of Offenders, held at Geneva in 1955, and approved by the Economic and Social Council by its resolution 663 C (XXIV) of 31 July 1957 and 2076 (LXII) of 13 May 1977.

8. Mullen PE, Briggs S, Dalton T, Burt M. Forensic Mental Health Services in Australia. International Journal of Law and Psychiatry 2000; 23: 433-452.

9. NSW Government. Mental Health Act 1990 No. 9 (Reprint No. 3). Sydney: NSW Government Information Service, 2000.

10. Birmingham L. Diversion from custody. Advances in Psychiatric Treatment 2001; 7: 198-207.

11. NSW Government. Mental Health (Criminal Procedures) Act 1990 No. 10. Sydney: NSW Government Information Service, 1995.

12. James D. Court Diversion at 10 years: Can it work, does it work, and has it a future? Journal of Forensic Psychiatry 1999; 10: 507-524.

13. Greenberg DM, Davies SR. Effectiveness of court based jail diversion for mentally ill detainees: A review. Unpublished.

14. Torrey EF, Stieber J, Ezekiel J, et al. (editors) Criminalizing the mentally ill: Abuse of jails as mental hospitals. Washington, DC: Public Citizen Health Research Group, 1992. 